\title{
Chapter 4 \\ Adaptation to Climate Change as a Key \\ Dimension of Urban Regeneration \\ in Europe: The Cases of Copenhagen, \\ Vienna, and Madrid
}

\author{
Sonia De Gregorio Hurtado
}

\begin{abstract}
Urban regeneration emerged during the 1990s as a policy area aimed at addressing urban decay through a novel approach to overcoming the limitations rooted in physical sectoral transformation. From that point on, a number of integrating mechanisms and relevant topics have emerged in this field, aimed at resolving current urban problems. At this juncture, when climate change has now been recognized as one of the most pressing urban challenges, urban regeneration needs to integrate adaptation to climate change as a crucial basis for action toward resilient urban transformation. This study springs from the recognition of the relevance of this policy approach, the analysis of which is undertaken focusing on three European cities - Copenhagen, Vienna, and Madrid - to understand whether and how the three municipalities are currently integrating adaptation to climate change within their urban regeneration programs. This objective is addressed through a mixed qualitative methodology that uses the case study approach to analyze the policy process, drivers, and obstacles that are fostering or limiting that vision in each local context. The research responds to the questions posed, showing the transformative capacity of integrating adaptation explicitly in the "common" regeneration practice of municipalities, the relevance of the development of local capacity as a crucial element for that, and other main factors that enable cities to advance or keep rooted in "traditional practices."
\end{abstract}

Keywords Urban regeneration - Adaptation to climate change Adaptive urban regeneration · Local capacity

\footnotetext{
S. De Gregorio Hurtado $(\square)$

Department of Urban and Spatial Planning, Faculty of Architecture, Universidad Politécnica de Madrid, Madrid, Spain

e-mail: sonia.degregorio@upm.es
} 


\subsection{Introduction}

Demographic urban stabilization in Europe, unsustainable land use for urban expansion, and the increasing vulnerability of specific neighborhoods over the last three decades are three of the main reasons that explain why cities are focusing their urban planning and policy on the improvement of the existing city. This trend has its roots in the 1980s, when structural changes in the economy and society pointed out to the necessity of giving a meaning and a future to existing urban areas (Secchi, 1984). The transformation of specific neighborhoods of European cities during the 1980s and the early 1990s resulted in the search for a new way to address urban decay, capable of overcoming the limitations identified so far. At that moment, urban regeneration emerged as a concept aimed at introducing a different approach to solving the main problems of deprived urban areas, adopting a vision significantly influenced by the so-called "collaborative turn" and transformation in local governance (Healey, 1996), along with the adoption of a holistic view toward sustainable development, enshrined in the Rio Summit of the United Nations in 1992 and its Declaration.

As urban regeneration is a policy field strongly, and essentially characterized by an integrated holistic approach (Informal Ministerial Meeting for Urban Development of the EU, 2010), it adopts a vision that comprehensively takes into account the relations between the different aspects of degradation in urban areas (Roberts \& Sykes, 2000). This vision has pointed to urban regeneration as an opportunity to solve the problems that lead to decline and vulnerability in deprived neighborhoods (Alpoppi \& Manole, 2013; Lehmann, 2019).

The main drivers that result in negative impacts in urban areas are profoundly related to global trends that have local consequences. Observing this framework, Roberts and Sykes (2000) argued that the "new" challenge for urban regeneration, at that moment, was to contribute to the achievement of sustainable development. At this juncture, there is no doubt that sustainability embraces new factors related with all the relevant aspects of climate change and energy in urban environments (Bulkeley, 2012; Lehmann, 2019). Consequently, it can be argued that adaptation to climate changes is today a new challenge to urban regeneration, a new dimension that requires to be fully integrated within urban regeneration policies.

Urban regeneration can address many of the challenges posed by climate change (Lehmann, 2019; UNU-Institute of Advance Studies, 2010) as it can provide essential and effective solutions toward making our cities more resilient (Ncube, 2011; Pearson, Newton, \& Roberts, 2014) acting in the four key dimensions of urban sustainable development through its integrated approach: the physical, social, economic, and governance dimensions. In this regard, the literature points out that urban regeneration projects can facilitate the implementation of spatial policy responses to adapt to the consequences of climate change in cities (Puppim de Oliveira \& Balaban, 2013). It can also act on the social, cultural, and economic dimensions of adaptation to climate change and contribute to reviewing the 
mechanisms of governance that determine this, for example, through the creation of local partnerships (Harman, Taylor, \& Lane, 2015; Taylor \& Harman, 2016).

Moreover, the very essence of urban regeneration leads us to consider that, due to its comprehensive nature, urban regeneration strategies need to integrate adaptation to climate change. Otherwise - and because of the relevance of this challenge those strategies would be biased and not able to give a place to comprehensive responses toward enduring positive transformation.

The review of the literature on urban regeneration and climate change for this study reveals that contributions addressing this topic have been insufficient so far. This confirms the relevance of focusing attention on integrating adaptation to climate change within the "common" practice of urban regeneration from an academic standpoint. It can contribute to filling relevant research and policy gaps, as well as giving visibility to this issue.

This study has found that most of the analysis undertook by the literature on local adaptation focus mainly on planning issues and the necessity to integrate adaptation to climate change in urban planning instruments (Zucaro \& Morosini, 2018). Other studies focus on different physical dimensions of urban regeneration: urban design and its capacity to adapt to climate change (Palazzo \& Wan Mohd Rani, 2017); adaptation in urban regeneration as a way to manage flood risks and deliver water sensitive cities (Chelleri, Schuetze, \& Salvati, 2015; Radhakrishnan, Pathiran, Ashley, Gersoniur, \& Zevenbergen, 2018); the capacity of urban green spaces or urban agriculture as elements to adapt cities to climate change (García Sánchez, Solecki, \& Ribalaygua Batalla, 2018; Mancebo, 2018); and how greening the built environment can accelerate an urban transition (Boeri, Gaspari, Gianfrate, \& Longo, 2017; Wilkinson, James, \& Reed, 2009). Some studies address the collaborative dimension of urban regeneration, in particular, the capacity of local partnerships to advance toward adaptive scenarios (Harman et al., 2015; Taylor \& Harman, 2016). Finally, there are relevant studies that have examined initiatives where urban regeneration includes adaptation to climate change as a key dimension (Ncube, 2011; Puppim de Oliveira \& Balaban, 2013). These are aligned with this study, but make a different contribution.

The fact that urban regeneration constitutes a specific policy field recognized by theory (Jones \& Evans, 2008; Roberts, Sykes, \& Granger, 2016) and practice (Couch, Fraser, \& Percy, 2003; Jones \& Evans, 2008) contrasts with the low attention paid to it by the literature and the practice from a climatic perspective. Nevertheless, it can play a key role in this regard because most big and medium EU cities implement instruments of urban regeneration.

The identification of this lack of attention to the issue has led to the research objectives of this chapter: (i) to understand if and how cities in Europe are integrating adaptation to climate change within their urban regeneration instruments and (ii) to analyze the main factors that explain this integration (or lack of).

In order to achieve these objectives, the research has developed a mixed qualitative methodology. In the first phase, the study focused on the identification of currently operating programs of urban regeneration in capital cities in Europe, while in the second phase the work focused on the development of three case studies for the 
cities of Copenhagen, Vienna, and Madrid. The study is structured as follows: Sect. 2 presents the conceptual framework in which the theoretical and practical interrelations between urban regeneration and adaptation to climate change are highlighted; Sect. 3 explains the methodology; Sect. 4 introduces and develops the case studies, summarizing the results and their discussion; and Sect. 5 presents the conclusions.

\subsection{Conceptual Framework}

\subsubsection{Urban Regeneration}

From the 1990s, urban transformation has been undertaken by municipalities, along with other stakeholders, in two main ways:

1. Through the designing of policies and instruments that fall within the domain of "urban regeneration." Often, in these cases, cities place urban regeneration at the heart of their holistic approach to sustainable urban development. Relevant action in this regard, in Europe, over the last decades enables us to state that: the most important interventions targeting urban areas have not only considered sustainable urban development, but have also focused on regeneration (Alpoppi \& Manole, 2013: 179).

2. Through transformative actions implemented with the use of sectoral instruments that are intended to overcome specific existing problems.

Commonly, cities take public action to improve their existing neighborhoods by combining both approaches. This study focuses on the first of these.

As mentioned earlier, the concept of urban regeneration emerged in the framework of a structural transformation of the economy and society that was leading to major negative effects on cities (Hall, 1987). The term and meaning, it concealed, signaled in the shaping of a new area of public policy that aimed to differentiate itself from other approaches to urban transformation that were specifically focused on physical renewal (Roberts \& Sykes, 2000). Against this backdrop, urban regeneration has been proposed as an alternative to the existing sectoral instruments with low participation of municipalities and local communities. This also featured an area-based approach, and the necessity to base concerted action on an integrated diagnosis.

As a strategic approach, urban regeneration sets the objective to be achieved and designs strategies that require to be formalized through concrete measures. In 2000, after relevant experience from 1989 onward, this vision became embedded in the framework of the urban dimension of EU Cohesion Policy. It was from that context that, in 2007, the term "integrated urban regeneration" was formalized. This concept is now widely used. Its conceptualization was made definitively explicit and disseminated through the Toledo Declaration (Informal Ministerial Meeting on Urban Development of the EU, 2010). The literature provides 
definitions of urban regeneration that are importantly aligned with the Toledo Declaration (even if presenting significant differences). For example, a definition widely disseminated, accepted, and referenced is the one proposed by Roberts et al. (2016):

Comprehensive and integrated vision and action which seeks to resolve urban problems and bring about a lasting improvement in the economic, physical, social and environmental condition of an area that has been subject to change or offers opportunities for improvement. (Roberts et al., 2016: n.a.)

These authors also consider that urban regeneration is characterized by an integrated approach and adopts an area-based vision. All these elements are also present in other definitions with slight differences (e.g., Aparicio Mourelo \& di Nanni, 2011; Couch et al., 2003; Moya \& Díez, 2012). The definitions by Aparicio Mourelo and di Nanni (2011) and Moya and Díez (2012) put specific attention to acting in vulnerable/deprived areas. This is also a relevant feature of the Toledo Declaration that highlights the fact that deprived urban areas:

$[\ldots]$ are not to be seen as a problem, but as a source of untapped human talent and physical capital whose potential has to be unlocked [...] (Informal Ministerial Meeting on Urban Development, 2010: 7).

through urban regeneration processes. As a result, the document conceptualizes an approach to urban regeneration that clearly considers the relevance of focusing on the most vulnerable areas of cities in the EU. These are also the areas that are the most vulnerable to climate change (Sánchez \& Guerrero Lemus, 2017), those that have a greater need of a vision leading to a higher level of climate adaptation capacity.

A relevant feature of urban regeneration that emerges implicitly from all the definitions mentioned, particularly important in the framework of this work, is that it aims to create local capacity through the implementation of a participative process in which public authorities, practitioners, and technicians interact with the local community. All these stakeholders develop new skills, knowledge, and experience, allowing them to continuing the beneficial effect of the urban regeneration program (beyond its life span), and to facing future negative trends. Because of this, urban regeneration is a public policy with strategic potential to improve the adaptive capacity of local communities.

\subsubsection{Adaptation to Climate Change in the Framework of Urban Regeneration}

In the last decades, climate change has been recognized as one of the most pressing challenges of humanity with relevant consequences for cities. It is now widely recognized that cities need to face its effects, particularly those related with the extreme weather events, but also those that are transforming climatic conditions in urban areas in a slower and lower degree. The literature recognizes that: 
local authorities are intensifying efforts to design climate policy that includes effective climate change adaptation [but at the same time points out that the] translation of policy into effective actions $[\ldots]$ faces barriers, and is proving to be a true challenge. (Simonet \& Leseur, 2018: 1)

This is also reported in the case of specific adaptation plans (Reckien, Salvia, Heidrich, Church, et al., 2018). The literature shows that while many cities in Europe are already working on mitigation, adapting to climate risks is a novel challenge for most of them (EEA, 2016; Reckien et al., 2018).

In any case, the negative socioeconomic and ecologic consequences of climate change are leading cities to face adaptation from different areas of action. Cities are addressing adaptation to climate change in different ways: (i) The most explicit one is the development of local plans for climate adaptation (Reckien et al., 2018); (ii) Many cities are also trying to mainstream the adaptation to climate change in urban planning. This is because urban planning and design are considered key determinants to limit the impacts of climate change (Jabareen, 2015) by acting on the physical dimension of vulnerability and exposure to risks. Municipalities are also trying to integrate the adaptation to climate change in other sectoral policies (mobility, social cohesion, housing, etc.).

In the framework of this work, it is relevant to note that when it comes to urban regeneration it is possible to see that, even if this is a domain in which generally big and medium European cities are active, there is a lack of explicit integration of the adaptation to climate change in their regeneration strategies. For example, in the work conducted by Reckien, Flacke, Dawson, Olazabal, et al. (2013), looking to the thematic areas of action included in the adaptation local plans in 200 European cities, urban regeneration did not arise as a policy field in which municipal authorities aimed to integrate adaptation to climate change. This fact limits the delivery of urban regeneration programs. On the contrary, the advancement toward programs of regeneration that integrate climate adaptation has a long-term transformative capacity. This is because this vision integrates into urban regeneration the adaptive capacity to climate change as an explicit objective, mobilizing technical, economic, and relational resources for that.

Smit et al. (2001: 881) define adaptive capacity as "the potential or ability of a system, region, or community to adapt to the effects or impacts of climate change." Urban regeneration, because of its integrated vision and its participative approach, has a real potential to increase the adaptive capacity of the area in which it operates, building capacity for urban adaptation, in the sense pointed out by Carter et al. (2015) in the framework of scenarios characterized by climate change and uncertainty (Lampis, 2013). The potential of integrating adaptation to climate change in urban regeneration is not limited to physical transformation. As it is a holistic practice, it is a fertile and coherent policy ground to understand and integrate the complex nature of climate adaptation, avoiding the fragmented vision that "overlooks the multidisciplinary nature of the issue" (Jabareen, 2015: 40).

As mentioned earlier, the literature has addressed this topic in a limited way. Some visions on the issue recommend a different approach to the one adopted by this 
study. They ask for a change of focus from urban regeneration to adaptation. In contrast, this study departs from the relevance of maintaining and enhancing urban regeneration as a relevant policy field, in which adaptation to climate change is integrated into an overall vision to advance toward the improvement of deprived neighborhoods. For that, building on the definitions mentioned (see Sect. 2.1), this work proposes the following definition of urban regeneration:

Integrated action, characterized by a multi-agent collaborative process, whose objective is the lasting improvement of the economic, physical, social, climate, and governance dimensions of a vulnerable urban area adopting an area-based approach and through the construction of local capacity.

This definition is proposed to municipalities and stakeholders that operate in urban regeneration to integrate the climate dimension (not only adaptation but also mitigation) explicitly in their urban regeneration practice.

\subsection{Methodology}

In order to achieve the objectives mentioned, the work has adopted a mixed qualitative methodology that has been structured into two phases:

In the first phase, the study aimed to identify currently running programs of urban regeneration. The research focused the analysis at this stage on the cities that have more capacity to integrate adaptation to climate change in urban regeneration. These are the cities with more potential to innovate and with more financial, technical, and institutional capacity and experience in running complex urban policies and instruments. This decision led to selecting a sample of capital or economic capital cities of European countries.

The search mapped urban regeneration initiatives in nine EU capital or economic capital cities of the EU (see Table 4.1). They were analyzed to understand the level of introduction of adaptation to climate change.

The programs' analysis identified three different levels of adaptation to climate change in urban regeneration (see Sect. 4). It was then decided to run case studies focusing on each of these levels. The selection of cities was based on the following criteria: (1) focusing on one city for each level of integration of adaptation to climate change in urban regeneration; (2) sufficient secondary sources to develop the analysis; (3) availability to develop interviews to public servants and/or technicians in the three municipalities. The cities selected for the development of the case studies were finally Copenhagen, Madrid, and Vienna.

In the second phase, the research designed the protocol for the development of the case studies and applied it to the three cities mentioned. The case study was selected as the method to undertake this part of the work as it allows to investigating the phenomenon under study in relation with its urban context using different sources of evidence. The objective was to understand the level of integration of adaptation to climate change in urban regeneration programs, and the policy and 
Table 4.1 Urban regeneration programs in the cities addressed in the first phase of the study

\begin{tabular}{l|l|l|l}
\hline City & Country & Name of the urban regeneration initiative/program & $\begin{array}{l}\text { Government } \\
\text { level }\end{array}$ \\
\hline Brussels & Belgium & Zone de Revitalisation Urbaine (ZRU) & Regional \\
\hline Berlin & Germany & Transformation areas & Municipal \\
\hline Copenhagen & Denmark & Integrated Urban Renewal Projects & Municipal \\
\hline Lisbon & Portugal & $\begin{array}{l}\text { Estratégia de Reabilitaçao Urbana de Lisboa } \\
2011 / 2024\end{array}$ & Municipal \\
\hline Madrid & Spain & $\begin{array}{l}\text { Plan Madrid Regenera. Estrategia de Regeneración } \\
\text { Urbana }\end{array}$ & Municipal \\
\hline Milan & Italy & Bando alle Periferie & Municipal \\
\hline Paris & France & $\begin{array}{l}\text { Les Projects de Renouvellement Urbain: GPRU, } \\
\text { NPNRU }\end{array}$ & Municipal \\
\hline Vienna & Austria & Gründerzeit Action Plans & Municipal \\
\hline Warsaw & Poland & Rewitalizacja w Warszawie & Municipal \\
\hline
\end{tabular}

implementation process for this, as well as drivers and limitations. In order to achieve this, the development of the case studies was based on the storyline analysis, as it "identifies assumptions and logics underlying the choice of particular policy directions over others" (MacCallum, Babb, \& Curtis, 2019: 194) building on an inductive work based on the analysis of policy documents. The gaps of information identified in the policy documents were filled through semiopen interviews to public servants (see Acknowledgments).

The summary of the results and the discussion of the case studies are reported in Sect. 4. Each case has been structured in two main parts that allow understanding if and how the practice of urban regeneration has evolved from a "traditional" approach to the integration of climate adaptation:

3. Contextualization of the city's urban regeneration policy. Plan of urban regeneration and its characterization (with a specific focus on adaptation).

4. Understanding if adaptation to climate change has been integrated (or not) into the urban regeneration plan of the city and how, with a specific attention to drivers and limitations. This part of the analysis focused on a specific area-based urban regeneration project in order to understand the level of embeddedness of the policy discourse developed in the policy documents in the transformation of concrete neighborhoods.

This work shows the results of the first stage of a wider study that will develop more case studies and will also focus on medium and small cities. The results achieved will determine important next steps, and are proposed as the basis for a reflection of a policy issue that is relevant in the current framework of climate emergence. 


\subsection{Adaptation to Climate Change in Urban Regeneration: The Cases of Copenhagen, Madrid, and Vienna}

As already mentioned, the research reviewed the action that was undertaken in the field of urban regeneration in nine cities (see Table 4.1). In most of them, the urban regeneration initiatives are launched by the local level (only in Brussels it was launched at the regional level). Cities develop urban strategies based on different temporal horizons $(2030,2050)$, as well as climate plans that include sectoral adaptive action. Predominantly, urban regeneration is not pointed out as a field to be taken into account in the adaptation to climate change.

The first insight into the cities' strategies, and their programs for urban regeneration, identified the fact that while Copenhagen introduced adaptation to climate change explicitly in its urban regeneration practice, the cases of Milan, Madrid, Brussels, Warsaw, and Lisbon presented measures that contributed indirectly to the adaptation to climate change without mentioning this dimension. These measures can be considered as part of a "traditional" view of urban regeneration, where physical transformation is prioritized. The cases of Berlin, Vienna, and Paris showed an intermediate position, where the vision analyzed in this study has been embedded within the discourse of policy documents, but has not been fully integrated within urban regeneration programs.

The research has developed the case studies of Copenhagen, Vienna, and Madrid in order to focus on the three levels of adaptation to climate change in urban regeneration identified by the study.

\subsubsection{The Case of Copenhagen}

\subsubsection{Contextualization of the City's Urban Regeneration Policy}

The municipality of Copenhagen has a tradition of urban regeneration that has operated over time under different names. In 2010, this public policy was unified under the term "integrated urban renewal" (Copenhagen Technical and Environmental Administration Urban Design Department, 2012: 4). The initiative was taken under a national law that allocated national funding to this objective. This policy action was aimed to act on the most vulnerable districts and was characterized by a clear area-based (Copenhagen Technical and Environmental Administration Urban Design Department, 2012: 7) and integrated approach.

The current integrated urban regeneration vision of the city can be considered as the evolution of the previous experience. The municipality has recognized and built on it, considering the integrated urban renewal projects as a sort of second generation of regeneration instruments. Each regeneration project sets up a local office (located in the area where the measures are being implemented) and a steering committee including local people among the other relevant stakeholders. Beyond this, 
the interdepartmental governance dimension of the strategy is addressed and a participation process is developed. All this effort is aimed at "empowering people. The partnership must become strong enough to cope with the future" (interview to Municipality of Copenhagen officer, 2019), as a path to construct local capacity.

Another important characteristic of this approach is the interest in involving different funding sources. Before the development of the strategy takes place, there is a preliminary task aimed at identifying potential investors (public and private). As a result, an investment statement is drawn up, covering the possibility for investment from the different stakeholders (Copenhagen Technical and Environmental Administration Urban Design Department, 2012).

The projects are structured in three different phases: (i) the start-up phase, in which participative working groups are created. It comprises the preparation of the district plan (strategy for regeneration of the area) and its approval; (ii) implementation, at this point, the ideas for the projects are planned in detail and implemented wherever possible; (iii) the anchoring phase, in which the future of the various activities and physical projects implemented is determined. In the framework of this study, it is relevant to note that the anchoring phase is extremely important in projects that aim to improve the adaptive capacity of urban areas to climate change to create local capacity.

The analysis of the regeneration practice of Copenhagen shows that it has built a sound method to improve vulnerable neighborhoods over time. In that experience, adaptation to climate change had been integrated indirectly through measures that aimed to improve urban spaces and the energy performance of buildings. This changed in 2011, as explained in the following section.

\subsubsection{Understanding if Adaptation to Climate Change Has Been Integrated (or Not) Into the Urban Regeneration Plan and How}

The explicit integration of the climate issue in urban regeneration took place from 2011 onward. The main reason mentioned in the gray literature and the interview (interview to Municipality of Copenhagen officer, 2019; Werner, 2014) was that, in July 2011, sudden torrential rain resulted in floods that affected large areas of the city. The neighborhood of Skt. Kjeld's was particularly affected. At that time, the city was implementing an integrated urban renewal project in that area. Due to the damages incurred by the flood, the municipality "changed the agenda and direction of the initiative," causing a "snowball effect" that resulted in the identification of Skt. Kjeld's as a "Klimakvarter" (climate resilient neighborhood) (interview to Municipality of Copenhagen officer, 2019) (see Fig. 4.1).

The planning expert for the municipality interviewed and the review of policy documents confirm that the climate pilot project of Skt. Kjeld's has evolved the previous experience of urban regeneration by integrating a climate adaptive concern and content. This is because the climate agenda has become a priority for the city (interview to Municipality of Copenhagen officer, 2019). Due to the importance of the project for the development of Copenhagen's urban approach toward including 


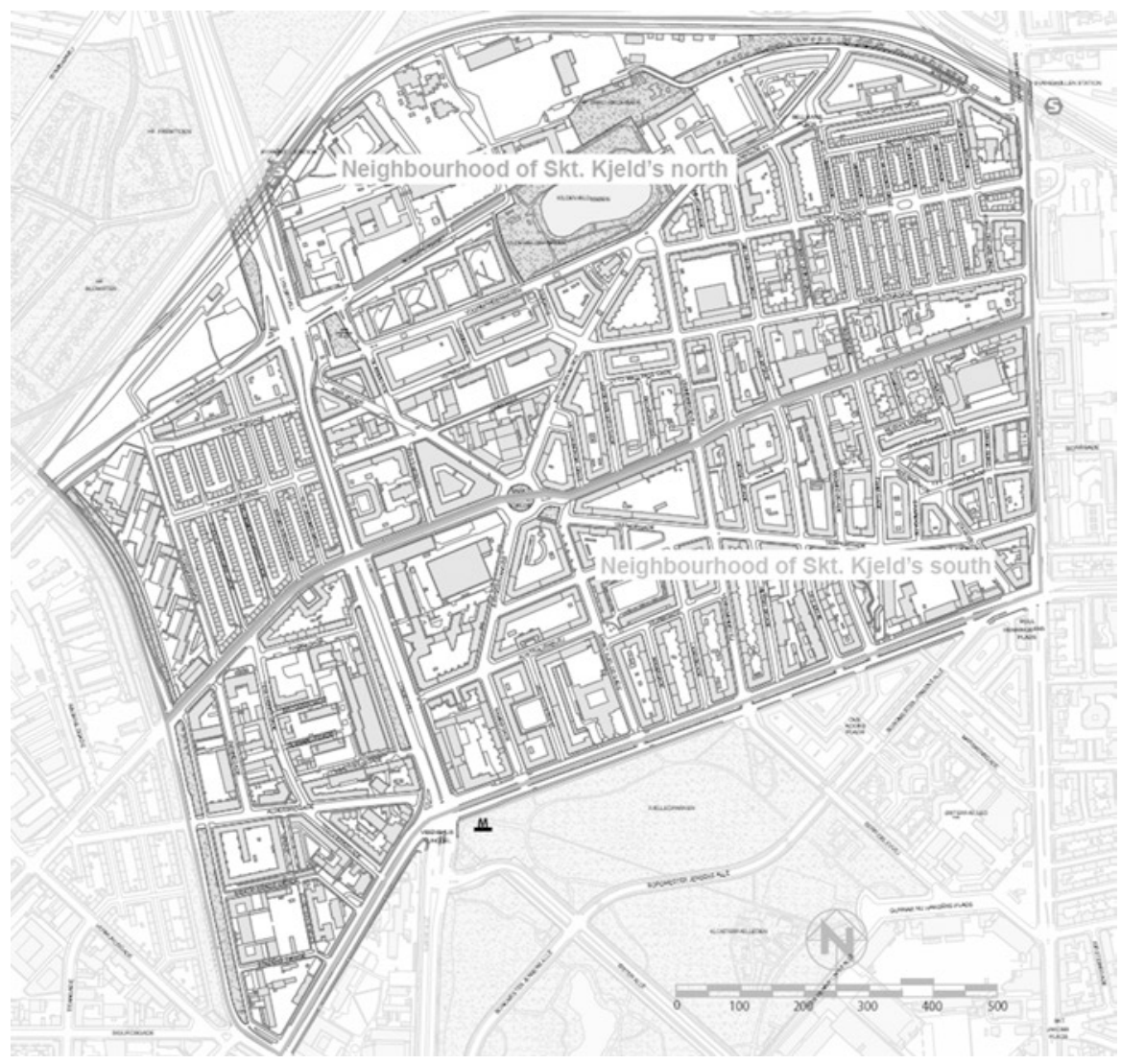

Fig. 4.1 The implementation area of the integrated urban renewal project for Skt. Kjeld's. (Source: The City of Copenhagen, The Integrated Urban Renewal in Skt. Kjeld's, 2011: 2)

adaptation to climate change as a crucial facet, and because it has been recognized as the initiator of this vision, it is relevant here to draw a comparison between the approach and measures of the initial project and the project that has finally been implemented under the "Klimakvarter" framework and that has complemented the measures originally planned: the initial project (that began in 2010) assumed that there was a need to overcome the "rundown" perception of Skt. Kjeld's district by making comprehensive physical improvements "to lead the way for additional moves designed to give the area a social lift" (Copenhagen Technical and Environmental Administration Urban Design Department, 2012: 51). The main measures showed an integrated approach, in which the physical and the social dimensions were prominent:

5. Improvement of the Skt. Kjeld's Plads and surrounding streets.

6. Provision of "activity and exercise belts which create better conditions for play, social interaction, and activity" (Copenhagen Technical and Environmental 
Administration Urban Design Department, 2012: 54). The many small open spaces were binding together.

7. Places for young people.

8. Project and media workshop (local volunteers helped to create projects for the development of the area).

9. Cultural laboratory.

10. Integration of the project with other municipal strategies. For example, regarding traffic and a cyclist route, the strategy was related to the traffic reduction planned by the Municipality for local streets and the extension of the Copenhagen Green Cycle Route through the district (Copenhagen Technical and Environmental Administration Urban Design Department, 2012).

As mentioned earlier, the regeneration approach embedded in this set of measures was complemented with new actions developed from the perspective of adaptation to "green climate" (Werner, 2014) under the "Klimakvarter" vision. This evolved urban regeneration approach was expressed in the words of the head of Technical and Environmental Affairs for the municipality:

We need to make Copenhagen more resilient to future cloudburst. This will require new ideas and solutions so that we can use rainwater to create new recreational urban spaces. (City of Copenhagen, 2011: 2)

The actions included were as follows:

11. $20 \%$ of the asphalted areas in the neighborhood to become green spaces that can be used for storm water management. Objective: $30 \%$ of everyday rain "managed locally on the surface in order to prevent pressure on the sewers" (City of Copenhagen, 2011: 5).

12. Transformation of Tasinge Plads (first climate change-adapted urban space) and Skt. Kjeld's Plads.

13. Creation of the green corridor of Bryggervangen.

14. Cloudburst roads defined as roads that in heavy rain events act as channels, diverting rainwater away from the buildings.

15. Creation of green courtyards.

16. Construction of a "climate resilient block" as a demonstration project for innovative scalable solutions aimed to find sustainable energy and climate solutions for buildings.

17. Citizens' own climate projects: taking advantage of the participatory process initiated in 2010, the initiative also builds on the involvement of the residents, so that they become jointly responsible for the initiative. For that purpose, the urban renewal office of the climate resilient neighborhood provides financial support and technical knowledge for projects initiated by residents (City of Copenhagen, 2011). Projects include city gardens and transformation of asphalted areas into green spaces.

The comparison of the measures of the two programs confirms the evolution of the urban regeneration concept for the city through the integration of climate change adaptation measures. Within this framework, particularly interesting was the 
intention to create local capacity through the involvement of citizens and the private sector in the design and delivery of adaptive measures. This is fully consistent with the vision for the city detailed within the 2015 municipal plan:

Together with the people [...] we will develop good, climate-adapted solutions that improve both everyday life and quality of life in the city as much as possible. It is important that all the city's projects focus on climate adaptation, especially those relating to regeneration $[\ldots]$ (City of Copenhagen, 2015: 40)

As a result of the action described in Skt. Kjeld's, the municipality reported that "the identity of the area is changing" due to the effect of the project (City of Copenhagen, 2015: 25). Interestingly, climate adaptation emerges in this case as an innovative driver capable to reverse the stigmatization of the area by redefining its identity. Beyond this, the initiative is creating an experience and knowledge that are starting to be transposed to other areas of Copenhagen. The project "has won several international awards" (The Climate Resilient Neighbourhood, 2016: 9) and has been recognized by other cities as an inspirational pathway (e.g., New York is currently implementing a similar concept, and C40 included the initiative in the list of the 100bestsustainableurbansolutions [TheClimateResilientNeighbourhood,2016]).

\subsubsection{The Case of Vienna}

\subsubsection{Contextualization of the City's Urban Regeneration Policy}

The city of Vienna based its approach toward urban regeneration on a vision described as "soft urban renewal" (City of Munich, 2014: 2) that had been developed over the previous four decades. It consists of an approach implemented by the Urban Renewal Offices through the Fund for Housing and Urban Renewal, with the aim of promoting rehabilitation programs, and focused originally on the improvement of relevant social housing stocks owned by the municipality (City of Munich, 2014; Stadt Wien, 2014).

Over time it has implemented interrelated actions aimed at the comprehensive improvement of entire residential blocks by combining housing redevelopment with other measures to improve living conditions more generally (Bretschneider, 2010). The "soft" vision of urban regeneration is based on a strong partnership principle that considers that all players have to be integrated within the process of transformation, moderate redensification, and strong social responsibility (City of Munich, 2014). It aims to preserve the existing population (preventing gentrification) and existing buildings and infrastructure.

The review of the literature on the issue confirms that the vision of urban regeneration in the city of Vienna has evolved from a sectoral one, focused on the physical dimension, and consisting of refurbishment of residential buildings, to an approach that aims to upgrade urban areas where initiatives form part of a more comprehensive vision. An example is the initiative "Together for Floridsdorf" that was launched in 2014 (Stadt Wien, 2014). In 2014, the municipality pointed out that 
"this action will decisively shape Vienna's urban renewal programme in the coming years" (Stadt Wien, 2014: 29). It was based on an approach that aimed to make the city districts "sustainably fit for the future" (Stadt Wien, 2014: 29) and was implemented in two areas: "Am Spitz Süd" and "Am Spitz Nord," in the district of Floridsdorf. The strategy of transformation consisted of the improvement of 11 buildings through a "socially orientated upgrade of the district" (Stadt Wien, 2014: 28). The action undertaken included structural refurbishment; enhancement of public space; reuse of ground floor premises; the achievement of social equilibrium in the district; and participation of the residents (Stadt Wien, 2014: 28). The regeneration strategy was integrated but did not explicitly address adaptation to climate change. It is relevant to note that the same approach can be found in the policy discourse embedded in the description of the urban regeneration vision of the city, explained in the Stadt Wien (City of Vienna) report in 2014 and 2015.

\subsubsection{Understanding if Adaptation to Climate Change Has Been Integrated (or Not) Into the Urban Regeneration Plan and How}

A subsequent Stadt Wien (City of Vienna) report (2016) adopted a more holistic view toward urban regeneration than the previous ones. In this report, the integration of environmental and sustainability dimensions turned its attention to climate change. The document mentions the relevance of the Paris Agreement of 2015. It is pointed to as a factor that influenced the urban policy agenda of Vienna significantly, by increasing awareness in local policymakers, and also in other stakeholders (interview to Municipality of Vienna officer, 2019). The conducted interview confirms this development, pointing out that "Since 2016 the topic of climate protection has gained a lot more attention and has become a higher priority" (interview to Municipality of Vienna officer, 2019).

In line with this, the 2016 document Housing in Vienna included the concept of "climate-friendly urban renewal" (Stadt Wien, 2016: 42) for the first time. This refers to measures taken on community heating, open spaces, e-mobility, and information and communications technology (ICT) solutions through clear liaisons with the Vienna's Smart City Framework Strategy (Stadt Wien, 2016) focused on standards of living, societal dimensions, and technological aspects.

The most relevant area-based project developed in this regard is that of Simmering (interview to Municipality of Vienna officer, 2019) (see Fig. 4.2).

It is particularly relevant to compare the action being undertaken under this initiative to the one for Floridsdorf. The project for Simmering shows a development toward a greater concern with climate issues, in which adaptation is not explicitly mentioned but rather given a more relevant presence. It comprises the following actions:

18. "Smart refurbishment" of three housing blocks with alternative energy generation, and implementation of e-car and e-bike sharing for residents. 


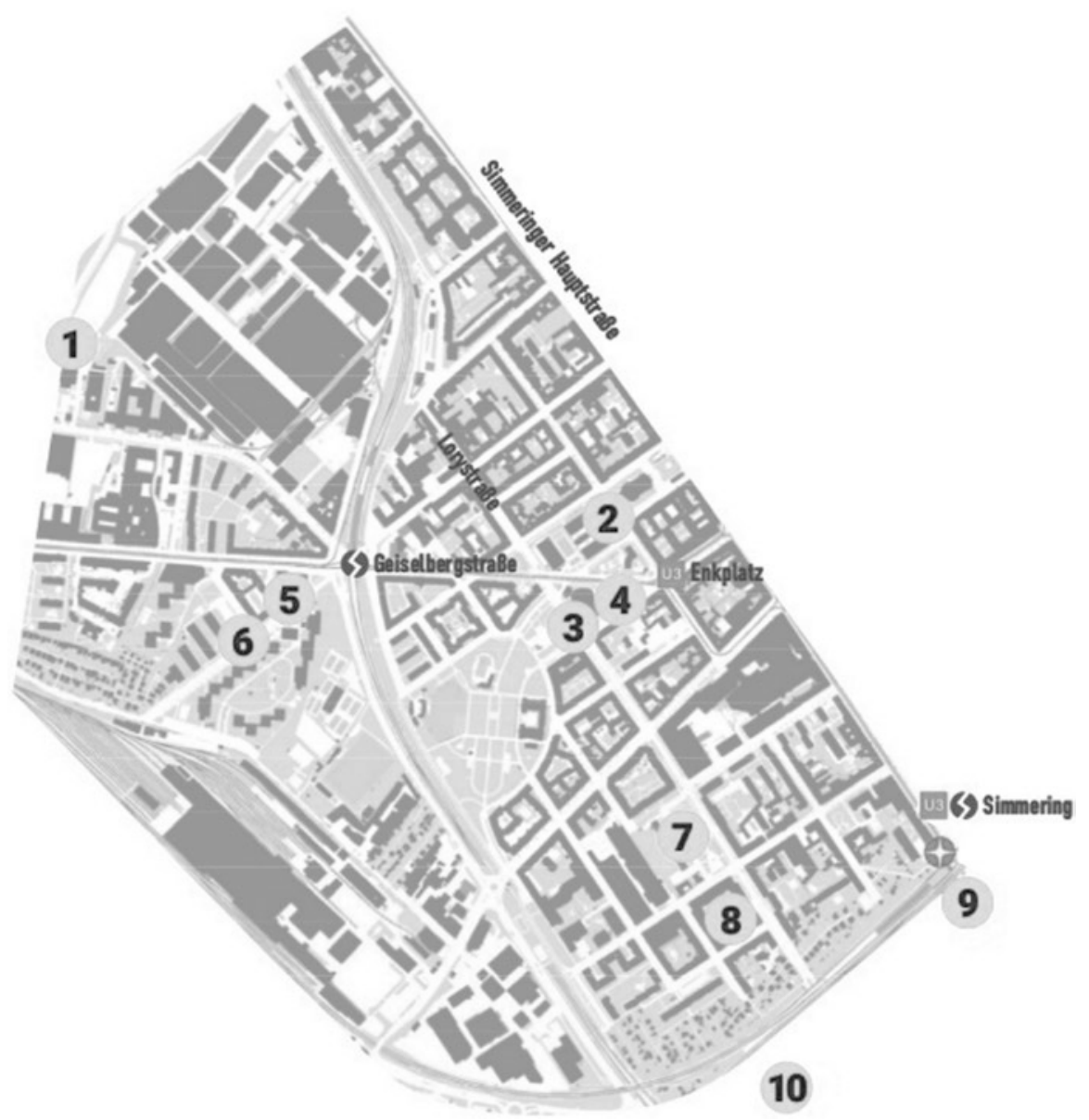

Fig. 4.2 Location of the different actions being implemented in the Simmering project. (Source: Adapted from City of Vienna, n.d.: 9)

19. Densification of district heating, including the local production of energy (photovoltaic and solar systems).

20. New secondary schools (with a new zero-energy gym complex).

21. City data platform contributing to Vienna's IT infrastructure.

22. Modernization of e-logistics and installation of charging infrastructure for e-cars and e-bikes.

23. Modern "mobility points" being prepared for use in public spaces to interlink local mobility services that suit users' needs.

24. Street lighting changed to LED lights.

25. "Landmarks" in the form of innovative street equipment with photovoltaic use (that allow people to charge their phones in public spaces) and aimed to draw attention to the project, making it more "visible." 
26. Implementation of the "mobile information lab SIMmobil" as a communication platform to offer comprehensive information and the chance for residents to be involved in the project.

27. "The lessons of knowledge and innovation will be put to use on a city-wide and international basis" (Stadt Wien, 2016: 42). This is because this project is integrated within the Smarter Together project (funded under Horizon 2020), the largest urban renewal project funded by the EU, and in which Vienna is exchanging knowledge and experience with other EU cities, such as Munich and Lyon.

The project has a clear "smart city" profile, in which the integration of new technologies is at the core of the solutions envisaged, showing that this is also a sector from where cities can propose to advance toward urban regeneration processes that integrate adaptation to climate change. In any case, adaptation to climate change has not been explicitly integrated, or made visible. Significantly, the document that reports on the action undertaken in this framework up to 2019 is entitled "Simmering. Smart Urban Renewal" (City of Vienna, 2019). The project partnership consists of 12 partners (the municipality, research institutions, private technology companies, etc.) that work together to design and implement the mentioned measures.

The analysis of the urban regeneration policy discourse in Vienna reveals the major influence of growing climate concerns and international agreements achieved on this issue. It can also be noted that this new urban regeneration approach has evolved through the years toward a vision in which the climate dimension in urban regeneration has been increasingly recognized and fostered through advancement in environmental (interview to Municipality of Vienna officer, 2019) and smart solutions. This vision appears nowadays as fully embedded in the policy discourse of the municipality. At the present moment, the city is undertaking a policy of adaptation to climate change on the basis of its 2010-2020 Climate Protection Plan II (Klimaschutzprogramm, KliP II). A relevant element that will contribute to it is the city, recently approved, Urban Heat Island Strategy (City of Vienna, 2018), an instrument that aims to "show planners, architects and the relevant administrative departments which actions can be implemented within their sphere of influence" (City of Vienna, 2018: 9). The philosophy of the plan is that action to reduce the Urban Heat Island effect can be selected and implemented "early" on, in different planning and urban development processes (City of Vienna, 2018), where urban regeneration can play a crucial role. The plan states that "climate change adaptation must be integral to planning, to increase the amenity of public spaces and improve the urban climate" (City of Vienna, 2018: 18), underlining its coherence with the Urban Development Plan 2025 (STEP 2025), where it is also mentioned that the city's aim is that climate protection and adaptation to climate change should become an integral part of the planning, implementation, and development of city neighborhoods and open spaces (City of Vienna, n.d.). In line with this intention, and fully integrated within the political discourse, the city is advancing toward adaptation to climate change in the practice of urban regeneration, a move described as "completely necessary" (interview to Municipality of Vienna officer, 2019). 
Nevertheless, there are some limitations to meet this horizon with regard to governance and implementation issues. The most relevant are the necessary involvement of a number of government departments that have traditionally worked independently and the division of the budget available, which requires a crossfunding vision to implement adaptive actions that come under the jurisdiction of different stakeholders (e.g., energy rehabilitation for housing, improvement of public areas, etc.) (interview to Municipality of Vienna officer, 2019). This is pointed to as an "internal challenge for Vienna" at the current moment, together with the necessary advancement in technical capacity within local public institutions (interview to Municipality of Vienna officer, 2019). It is pointed out that the benefits of integrating adaptation to climate change in urban regeneration are only visible in the medium term. Consequently, it is considered that climate awareness raising among technical staff, society at large, and other relevant stakeholders, in the context of urban regeneration, is also a transformative and key target to be achieved (interview to Municipality of Vienna officer, 2019).

\subsubsection{The Case of Madrid}

\subsubsection{Contextualization of the City's Urban Regeneration Policy}

The city of Madrid does not have a tradition of urban regeneration. Public action toward urban transformation has gone ahead over time on the basis of sectoral instruments to improve the quality of public spaces, to construct or refurbish buildings, to offset the shortfall in facilities and public services, and to improve the standards of the housing stock, along with social and economic policies. This scenario changed in 2018, when the Government Area of Sustainable Urban Development (AGDUS) launched the strategy for urban regeneration integrated in the Madrid Recupera Plan (Plan MAD-RE), an instrument aimed to improve the existing neighborhoods, in line with the New Urban Agenda and the UN Sustainable Development Goals (SDGs) (Ayuntamiento de Madrid, 2018) and in pursuit of the main objective of overcoming the traditional urban policy based on urban expansion (Ayuntamiento de Madrid, 2018). The instrument adopts the concept of "integrated urban regeneration."

Seeking explicit alignment with the UN's New Urban Agenda, the Plan MAD-RE focuses on the area of the city located between the city center and the new urban developments, where it is considered that vulnerability is concentrated. The initiatives proposed are spread across the different districts of the capital, under different categories and form. Only few of them adopt an area-based approach.

The Plan MAD-RE, which sets down the main goals for action over the years to follow, does not explicitly consider adaptation to climate change as a specific facet within urban regeneration projects (Ayuntamiento de Madrid 2018; interview to Municipality of Madrid officer, 2019). It sets the following elements as its main focus in its proposals for urban regeneration: (1) rehabilitation of buildings and 
neighborhoods; (2) the creation of central areas in the peripheries; (3) a new mobility culture; (4) the requalification of public space; and (5) the reinforcement of a green areas network. As a result, it can be said that it adopts a strong physical approach, far from a real integrated vision.

\subsubsection{Understanding if Adaptation to Climate Change Has Been Integrated (or Not) Into the Urban Regeneration Plan and How}

The introduction of the adaptive view is implicit in the Plan MAD-RE, as it funds energy rehabilitation in buildings, the improvement of public space, and the reinforcement of the green areas network under a renaturalization approach (interview to Municipality of Madrid officer, 2019). The implicit vision mentioned is also embedded in the fact that the plan's strategy has a global intention, aiming to achieve the integrated regeneration of deprived or vulnerable neighborhoods. Consequently, it is expected that the action within the Plan MAD-RE will be added to with other sectoral strategies developed by other municipal departments. To achieve this objective, the plan needs to be coordinated with the plan on air quality and climate change for the city and the plan Madrid + natural (both of them coming within the scope of the Government Area of Environment). While the first is aimed at mitigating carbon emissions, the second has a specific focus on adaptation to climate change through the development of nature-based solutions (NBS). In fact, the plan Madrid + natural is considered by the municipality as a vision of innovation and urban regeneration through NBS. The complementarity of the plan Madrid + natural with the strategy of urban regeneration has resulted in one pilot project entitled "Del Río a Pradolongo" (from the river to the Pradolongo park), an itinerary that links up two green areas, and that will be transformed through the improvement of public spaces, with a specific focus toward adaptation to climate change. It involves the collaboration between two government areas of the municipality, something that is difficult to implement at a general scale (interview to Municipality of Madrid officer, 2019).

The review of the plan has set the focus of this study on one of the few area-based initiatives with sufficient level of implementation to be considered of interest to this analysis: the transformation foreseen for the area located close to Madrid's airport, the Barrio del Aeropuerto. The area is located in the north-east of Madrid. Because of the physical problems of the level of conservation and lack of universal accessibility to the buildings, the state of public spaces, and recurrent flooding (due to the presence of an underground stream), this area has been subject of an urban regeneration strategy that focuses on the buildings, public spaces, and the existing social fabric (interview to Municipality of Madrid officer, 2019) in the framework of the Plan MAD-RE (see Fig. 4.3).

The strategy is a participated project importantly based on the physical transformation, in which the social and the economic dimensions are not explicitly addressed (because of the lack of competences of AGDUS on social and environmental issues) [interview to Municipality of Madrid officer, 2019]). Because of this, the transformation foresaw cannot be labeled strictly as "integrated" urban regeneration under 


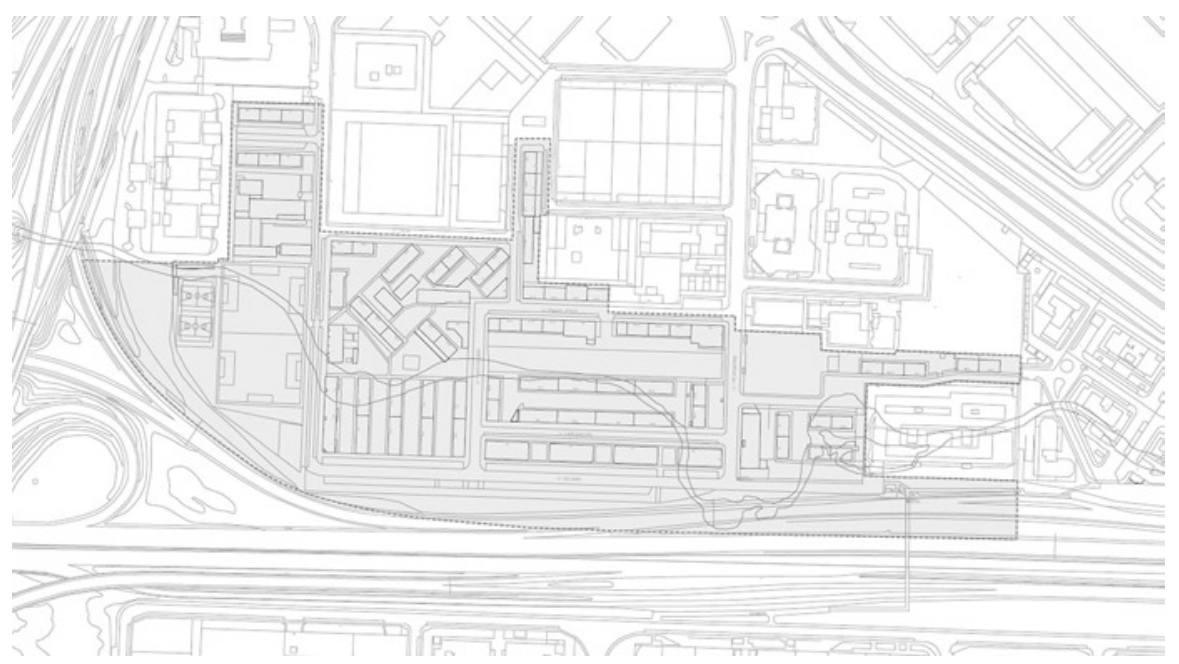

Fig. 4.3 The area of implementation of the urban regeneration project of Barrio del Aeropuerto. (Source: Adapted from Ayuntamiento de Madrid, 2017)

the lens of this study. The main measures included in the project are the following: elevators installation, refurbishment and energy rehabilitation of the residential buildings, improvement of the public space, creation of a new green area to avoid flooding, and creation of new public facilities. The project foresees also the construction of two new housing buildings that will generate capital gains to face the planned transformation.

The project to regenerate the Barrio del Aeropuerto does not integrate adaptation to climate change as a specific area of action. The issue is not mentioned in any of the documents that define or summarize the proposals, approach, and outcomes of the participatory sessions, or in the gray literature. As a result, and in line to what emerges from the approach of the Plan MAD-RE, it could be said that the project only addresses adaptation to climate change through the indirect effect of certain physical measures that will contribute to better adapting it to more extreme hot temperatures and flooding.

While there is no doubt about the contribution that the project will make in this regard, the program's lack of specific integration of adaptation to climate change limits importantly the potential of the solution. In this sense, opportunity to give a place to public awareness raising with regard to adaptation to climate change through participation-based sessions has been lost. The lack of participative and integrated approach arises in this case as a factor importantly related with the limited transformative capacity of the project from an adaptive point of view. This contrast with the view expressed by the technician interviewed, who pointed out that explicit integration of adaptation to climate change should be present in urban regeneration programs in the future (interview to Municipality of Madrid officer, 2019). Nevertheless, to achieve this vision the municipality will need to overcome 
relevant limitations related with path dependence: (i) the policy silos and the division of competences among different areas of the local government that need to work together and (ii) the division of the budgets to implement integrated urban regeneration projects (interview to Municipality of Madrid officer, 2019).

\subsection{Conclusions}

In the group of nine main cities addressed in first phase of the research, the study identified three different levels of integration of adaptation to climate change in urban regeneration:

- Cities that have integrated adaptation to climate change as a specific axis in their strategy for urban regeneration. This dimension acts as a relevant innovation driver of the strategies.

- Cities that have integrated adaptation to climate change as a specific issue in its strategy for urban regeneration from a discursive point of view, and that is evolving toward full integration of this vision in the practice of urban regeneration.

- Cities that have not explicitly integrated adaptation to climate change, either in their policy discourse on urban regeneration or as a specific angle to be addressed in the practice of urban regeneration.

These three different levels of integration of the policy issue addressed are represented, respectively, by the cities of Copenhagen, Vienna, and Madrid, the three case studies in which this research focused on. It is worth noting that the technical experts from the three cities interviewed point to the necessity of making adaptation to climate change explicit and visible in urban regeneration projects, as this can deliver a transformative adaptive local capacity in communities and institutions (interviews to Copenhagen, Vienna, and Madrid officers, 2019). They all underlined the urban regeneration potential of taking into account the physical, social, and economic dimensions of adaptation to climate change. This study identified that this vision has been fully embedded only in the case of Copenhagen. This case shows the relevance of identifying climate vulnerability at district level, and demonstrates the potential of involving the residents and the private sector in the design and implementation of adaptive measures (Harman et al., 2015) from the beginning in the context of regeneration programs. As a result, this case highlights the relevance of complementing traditional vulnerability indicators for the identification of the neighborhoods in which urban regeneration is more necessary, with climate change vulnerability indicators. It also shows that regeneration instruments based on a sound participative methodology and with a longer tradition on the implementation of the integrated approach (acting in the social, economic, physical, and governance dimensions) have the capacity to integrate adaptation to climate change as a new dimension.

In the case of Vienna, the municipality has undertaken a gradual commitment to adaptation to climate change that has been fostered by an awareness raising process 
resulting from the Paris Agreement reached at COP21, in December 2015, and the participation in EU research/implementation projects. It has also been given momentum from the urban planning, environmental and smart city dimensions of local policy. The issue is not explicitly addressed in the practice of integrated urban regeneration showing governance and budget limitations, but it can be considered that the relevance of this vision has been fully integrated within the urban regeneration policy discourse of decision makers. This fact, along with the existence of a solid climate policy, shows a trend to fully integrate adaptation to climate change in urban regeneration in the medium term.

In the case of Madrid, the international urban agendas, and particularly those of the United Nations, have introduced local action on urban regeneration to a great extent, but this has not resulted so far in embedding adaptation within the policy discourse developed by the city plan for urban regeneration. The city has not developed, so far, a really integrated urban regeneration experience, as the plan focuses mainly on physical transformation. The lack of an integrated and participative approach in urban regeneration is acting as an obstacle to transfer adaptive solutions tested in pilot projects to the general urban regeneration practice, and to embed adaptive awareness in the area-based interventions addressed by this study.

The analysis shows that two are the main problems arising when integrating adaptation to climate change as an explicit approach in urban regeneration projects: (1) the traditional policy silos determined by the organization of local administrations (that limits powers of government departments that manage urban regeneration strategies) and (2) the division of budget allocations. These facts are pointed out as relevant obstacles, in the cases of Vienna and Madrid, over the lack of institutional or local capacity. These facts have been also identified by the literature as limitations to implement local adaptation in general (Measham, Preston, Smith, Brooke, et al., 2011).

Taking all this into account, and because this study has identified that the nine programs of urban regeneration addressed include implicit adaptive measures based on physical transformation (even in the cases that show more limitations to the integration of adaptation to climate change), this work proposes to adopt a strategic approach in urban regeneration to advance to more adaptive urban futures in policy contexts that present an important inertia to change, and are highly determined by path dependence. It departs from the definition of urban regeneration proposed in Sect. 2.2. From the adoption of that vision, cities can define adaptation to climate change as an explicit dimension of their regeneration programs (even if they do not include specific measures tackling that challenge in the first stage). The proposal consists in integrating adaptation to climate change in two main ways at the beginning: (i) as a specific topic for reflection, discussion, and awareness raising within the participative processes that characterize urban regeneration projects and (ii) as a dimension to be taken into account in the definition of all the actions proposed within the projects, making explicit how "traditional measures" (as the energetic rehabilitation of buildings, or the planting of trees) contribute to adapt the city to climate change. This approach can allow cities to start an important policy transformation with regard to their climate action without requiring extra budget and 
without being limited by the policy silos. The proposal aims to activate the potential of urban regeneration to fully embed climate adaptation in future steps, developing local capacity gradually through an incremental transformation of the "traditional" urban regeneration vision.

Finally, the study shows that the integration of adaptation to climate change can act as a driver of innovation in urban regeneration (as identified in the case of Copenhagen and also, partially, in the case of Vienna). Jabareen's (2015: 39) argument regarding the broader practice of urban planning is also pertinent and valid for urban regeneration: "climate change and its resulting uncertainties challenge the practices and concepts" of urban regeneration, resulting in a need to rethink and revise it. This study confirms that the integration of adaptation to climate change in urban regeneration can make evolve this policy area, so that it is capable to give a response to one of the main urban challenges of our time.

Acknowledgments The author is grateful to COST Action RESTORE CA16114 that granted her research stay in the University IUAV of Venice during January and February 2019. The author is also grateful to the Planning Climate Change Lab that hosted the research stay, and thanks the technicians of the municipalities of Copenhagen, Vienna, and Madrid that were interviewed: Interview (A) Municipality of Copenhagen, interviewed on March 12, 2019; Interview (B) Municipality of Vienna, interviewed on June 6, 2019; Interview (C) Municipality of Madrid, interviewed on June 26, 2019.

\section{References}

Alpoppi, C., \& Manole, C. (2013). Integrated urban regeneration. Solutions for cities revitalize. Procedia Economics and Finance, 6, 178-185.

Aparicio Mourelo, A., \& di Nanni, R. (2011). Modelos de gestión de la regeneración urbana. Madrid, Spain: Sepes.

Ayuntamiento de Madrid. (2017). Nuevo planeamiento para la rehabilitación de viviendas del Barrio del Aeropuerto en Barajas. https://www.espormadrid.es/2017/05/nuevo-planeamientopara-la.html. Accessed 25 Jan 2019.

Ayuntamiento de Madrid. (2018). Madrid Recupera. Estrategia de Regeneración Urbana. 1 Memoria. Madrid, Spain: Ayuntamiento de Madrid. https://transparencia.madrid.es/portales/ transparencia/es/Organizacion/Planes-y-memorias/Planes/Plan-Madrid-Recupera-Estrategiade-Regeneracion-Urbana/?vgnextfmt $=$ default\&vgnextoid=251b21a54bf68610 VgnVCM1 000001d4a900aRCRD\&vgnextchannel=d869508929a56510VgnVCM1000008a4a900aRCRD. Accessed 20 May 2019.

Boeri, A., Gaspari, J., Gianfrate, V., \& Longo, D. (2017). Accelerating urban transition: An approach to greening the built environment. WIT Transactions on Ecology and the Environment, $223,3-14$.

Bretschneider, B. (2010). Comprehensive Urban Renewal: More than building regeneration. A case study in Vienna. In M. Schrenk, V. V. Popovich, \& P. Zeile (Eds.), Proceedings of the Conference Real Corp 2010 (pp. 1037-1044). Vienna 18-20 May 2010.

Bulkeley, H. (2012). Climate change and the City. London: Routledge.

Carter, J. G., Cavan, G., Connelly, A., Guy, S., Handley, J., \& Kazmierczak, A. (2015). Climate change and the city: Building capacity for urban adaptation. Progress in Planning, 95, 1-66. 
Chelleri, L., Schuetze, T., \& Salvati, L. (2015). Integrating resilience with urban sustainability in neglected neighbourhoods: Challenges and opportunities of transitioning to decentralized water management in Mexico City. Habitat International, 48, 122-130.

City of Copenhagen. (2011). Integrated urban renewal in Skt. Kjeld's. A neigbourhood in motion. Copenhagen, Denmark: City of Copenhagen. https://kk.sites.itera.dk/apps/kk_pub2/pdf/1114_ ZTt8DHZacf.pdf. Accessed 10 May 2019.

City of Copenhagen. (2015). City of Copenhagen municipal plan 2015. The Coherent City. Copenhagen, Denmark: City of Copenhagen. https://kp15.kk.dk/sites/kp15.kk.dk/files/municipal_plan_2015.pdf. Accessed 10 May 2019.

City of Munich. (2014). Vienna in dialogue about urban transformation. "Soft urban renewal" Moderate densification and dialogue. Munich, Germany: City of Munich.

City of Vienna. (n.d.). STEP 2025. Vienna: City of Vienna.

City of Vienna. (2014). Vienna housing. Annual report 2014. Vienna: Stadt Wien.

City of Vienna. (2016). Vienna housing. Annual report 2016. Vienna: Stadt Wien.

City of Vienna. (2018). Urban heat Island strategy. City of Vienna. Vienna: Vienna Environmental Protection Department.

Copenhagen Technical and Environmental Administration Urban Design Department. (2012). Integrated urban renewal in Copenhagen. Copenhagen, Denmark: Technical and Environmental Administration Urban Design Department.

Couch, C., Fraser, C., \& Percy, S. (2003). Urban regeneration in Europe. Oxford: Blackwell Publishing Company Ltd..

European Environmental Agency EEA. (2016). Urban adaptation to climate change in Europe 2016. Transforming cities in a changing climate. Luxembourg: EEA.

García Sánchez, F., Solecki, W. D., \& Ribalaygua Batalla, C. (2018). Climate change adaptation in Europe and the United States: A comparative approach to urban green spaces in Bilbao and New York City. Land Use Policy, 79, 164-173.

Hall, P. (1987). Las ciudades de Europa: ¿Un problema europeo? ¿Una profesión europea? Urbanismo, 1, 25-31.

Harman, B. P., Taylor, B., \& Lane, M. B. (2015). Urban partnerships and climate adaptation: Challenges and opportunities. Current Opinion in Environmental Sustainability, 12, 74-79.

Healey, P. (1996). The communicative turn in planning theory. In S. Campbell \& S. S. Fainstein (Eds.), Readings in planning theory (pp. 237-256). Oxford: Blackwell Publishing.

Informal Ministerial Meeting for Urban Development of the EU. (2010). Toledo declaration. https://ec.europa.eu/regional_policy/archive/newsroom/pdf/201006_toledo_declaration_ es.pdf. Accessed 25 Mar 2019.

Jabareen, Y. (2015). The risk city. Cities countering climate change: Emerging planning theories and practices around the world. Cham, Switzerland: Springer.

Jones, P., \& Evans, J. (2008). Urban regeneration in the UK: Theory and practice. London: SAGE.

The Climate Resilient Neighbourhood. (2016). Copenhagen's first climate resilient neighbourhood. Copenhagen, Denmark: Klimakvarter.

Lampis, A. (2013). Vulnerabilidad y adaptación al cambio climático: Debastes acerca del concepto de vulnerabilidad y su medición. Cuadernos de Georgrafía. Revista Colombiana de Geografía, 22(2), 17-33.

Lehmann, S. (2019). Urban regeneration. A manifesto for transforming UK cities in the age of climate change. London: Palgrave Macmillan.

MacCallum, D., Babb, C., \& Curtis, C. (2019). Doing research in urban and regional planning. Lessons in practical methods. New York/London: Routledge.

Mancebo, F. (2018). Gardening the city: Addressing sustainability and adapting to global warming through urban agriculture. Environments, 5(3), 38. https://www.mdpi.com/2076-3298/5/3/38. Accessed 16 Mar 2019.

Measham, T. G., Preston, B. L., Smith, T. F., Brooke, C., et al. (2011). Adapting to climate change through local municipal planning: Barriers and challenges. Mitigation and Adaptation Strategies for Global Change, 16, 889-909. 
Ministerial Meeting on Urban Development. (2010). Toledo declaration. Available in: https:// ec.europa.eu/regional_policy/archive/newsroom/pdf/201006_toledo_declaration_en.pdf

Moya, L., \& Díez, A. (2012). La intervención en la ciudad construida: acepciones terminológicas. URBAN, 4, 113-122.

Ncube, C. (2011). Climate change adaptation and EIA in UK urban regeneration projects. The future of EIA. Oxford: Oxford Brookes University.

Palazzo, E., \& Wan Mohd Rani, W. N. M. (2017). Regenerating urban areas through climate sensitive urban design. Advance Science Letters, 23, 6394-6398.

Pearson, L., Newton, P., \& Roberts, P. (2014). Resilient sustainable cities: A future. London: Routledge.

Puppim de Oliveira J. A., \& Balaban, O. (2013). Climate-friendly urban regeneration: Lessons from Japan. Development \& Society: Asia, Climate Change, Urban Development. 2013/08/28. United Nations University. Accessed 29 Jan 2019.

Radhakrishnan, M., Pathiran, A., Ashley, R. M., Gersoniur, B., \& Zevenbergen, C. (2018). Flexible adaptation planning for water sensitive cities. Cities, 78, 87-95.

Reckien, D., Flacke, J., Dawson, R., Olazabal, M., et al. (2013). Climate change response in Europe: What's the reality? Analysis of adaptation and mitigation plans from 200 urban areas in 11 countries. Climatic Change, 122(1-2), 331-340.

Reckien, D., Salvia, M., Heidrich, O., Church, J. M., et al. (2018). How are cities planning to respond to climate change? Assessment of local climate plans from 885 cities in the EU-28. Journal of Cleaner Production, 191, 207-219.

Roberts, P. y Sykes, H. (2000). Urban regeneration. Sage: London.

Roberts, P., Sykes, H., \& Granger, R. (2016). Urban regeneration . (Segunda ed.). London: Sage.

Sánchez, A. B., \& Guerrero Lemus, W. (2017). Cambio climático y salud. Mayor impacto en los más vulnerables. Observatorios de Salud y Medio Ambiente DKV Seguros. https://www.fundacionalternativas.org/public/storage/publicaciones_archivos/e0dde2355388586477952593bd 7de6d0.pdf. Accessed 22 Feb 2019.

Secchi, B. (1984). Le condizioni sono cambiate. Casabella, 498-499(1989c), 48-56.

Simonet, G., \& Leseur, A. (2018). Barriers and drivers to adaptation to climate change. A field study of ten French local authorities. Climatic Change, 155(1), 621-637.

Smit, B., Pilifosova, O., Burton, I., Challenger, B., et al. (2001). Adaptation to climate change in the context of sustainable development and equity. In J. McCarthy, O. Canziani, N. Leary, D. Dokken, \& K. While (Eds.), Climate change 2001: Working group II: Impacts, adaptation and vulnerability. Third assessment report of the intergovernmental panel on climate change (pp. 877-912). Cambridge, UK: Cambridge University Press.

Taylor, B. M., \& Harman, B. P. (2016). Governing urban development for climate risk: What role for public-private partnerships? Environmental and Planning c-government and policy, 34(5), 927-944.

UNU-Institute of Advance Studies. (2010). The role of urban regeneration in climate change adaptation. http://www.ias.unu.edu/sub_page.aspx?catID=1306. Accessed 15 April 2019.

Werner, S. (2014). Copenhagen climate adapted neighbourhood. Copenhagen, Denmark: City of Copenhagen.

Wilkinson, S. J., James, K., \& Reed, R. (2009). Using building adaptation to deliver sustainability in Australia. Structural Survey, 27(1), 46-61.

Zucaro, F., \& Morosini, R. (2018). Sustainable land use and climate adaptation: A review of European local plans. TeMa - Journal of Land Use, Mobility and Environment, 11(1), 7-26. 
Open Access This chapter is licensed under the terms of the Creative Commons Attribution 4.0 International License (http://creativecommons.org/licenses/by/4.0/), which permits use, sharing, adaptation, distribution and reproduction in any medium or format, as long as you give appropriate credit to the original author(s) and the source, provide a link to the Creative Commons license and indicate if changes were made.

The images or other third party material in this chapter are included in the chapter's Creative Commons license, unless indicated otherwise in a credit line to the material. If material is not included in the chapter's Creative Commons license and your intended use is not permitted by statutory regulation or exceeds the permitted use, you will need to obtain permission directly from the copyright holder. 